\title{
The evaluation of the attractiveness of marine container terminal sector: analysing the polish sector
}

\author{
Robert Marek $^{1, *}$ \\ ${ }^{1}$ Gdynia Maritime University, Poland
}

\begin{abstract}
The importance of attractiveness of the marine container terminal operators have significantly increased in the recent years due to them influence on the worldwide economy. This article aim is to evaluate the attractiveness of marine container terminals by using a qualitative analysis. The main point is to define the attractiveness of the Marine Container Terminal Operators (MCTOs) located in Poland. The qualitative analysis has provided arguments to conclude that marine container market in Poland currently is attractive from the point of existing MCTOs in this sector. The developed model helps to estimate the attractiveness of the marine container terminal market (MCTM) in Poland.
\end{abstract}

\section{Introduction}

Marine container terminal operators play an important role as a node in many logistic supply chains. These main players operate container transshipment between various transport modalities. The main modalities are deep-sea, short-sea, inland waterway, road and rail (mainly intermodal). Due to the globalization process, marine container flows worldwide are growing very rapidly and it is expected that this grow will be continue during the next decades. Moreover, a new generation of deep-sea cellular container vessels, with a capacity of $18000-21000$ TEUs, is coming into ship owner's operations. In the future, the vessels may reach cargo capacity 50000 TEU [1]. These growths and developments urge the main and minor marine container terminal operators to reconsider their equipment and logistics or even to expand. Consequently, currently the attractiveness of the marine container market in Poland has become a particularly relevant, thus influencing not only the market members, but the whole countries' economy as well. The MCTOs constitute rapid growth of their container's transshipment which involves longterm and medium-term investments into operational equipment and support hinterland connections. The attractiveness of the marine container market - the profit potential - is analyzed in accordance with MCTOs. The attractiveness of the marine container market is perceived as the capability to effectively compete in the world while improving most needs of major link in transport chain, the needs of both transport and shippers customers, higher levels of efficiency in land haulage and its infrastructures. The aim of this paper is to

\footnotetext{
* Corresponding author: r.marek@wpit.am.gdynia.pl
} 
identify, analyze, and evaluate the main factors influencing the attractiveness of marine container terminal operators which are operating in Poland. In order to achieve the aim, the following objectives have been put forward:

- to conceptualize the attractiveness of the marine container market;

-to identify and analyze the main factors influencing the attractiveness of the marine container market;

-to evaluate the main factors influencing the attractiveness of the marine container market in Poland;

In order to implement the objectives, a systematic and comparative analysis of the scientific literature, covering the attractiveness of marine container terminal operators, has been accomplished in the second section of the paper. The third section deals with the methodology of a qualitative research. The fourth section presents and discusses the results of the data qualitative analysis and the evaluation of the main factors influencing the attractiveness of the marine container terminal operators in Poland. The paper is completed with the conclusions based on the generalization of the research results concerning the attractiveness of the marine container terminal operators located in Poland.

\section{Literature Review}

One of the most inherent developmental features of the present maritime economy is the process of globalization based on the objective nature principle of causality, i.e. how certain activities in certain circumstances always create respective consequences. Globalization processes are seen as a result of the world states' development which opened up their economies and liberalized economic relations among the countries thus motivating the involvement and participation of national companies in the global economic system [2]. Upon joining the European Union in 2004, the Poland container market has become much more accessible to foreign marine container operators; this made it possible to attract internal as well as the foreign marine container terminal operators (MCTOs). The foreign MCTOs thoroughly analyze an unknown Polish market in order to determine whether such investment will be profitable, i.e. they determine the market attractiveness level. When analyzing the general definitions of market attractiveness presented by different authors, one should notice that even though they are quite different, the key factors determining the market attractiveness remain quite similar. The most business and marketing dictionaries define the market attractiveness assessment from the position of a customer, a company, or an investor, i.e. as a profit or benefit opportunity in a particular market or industry. The higher the potential gain or benefit, the more attractive a market is considered to be. The attractiveness of the market in other literary sources is very closely related to market competitiveness. According to the American Marketing Association dictionary, the market attractiveness defines the degree of market opportunities provided by a market segment and a company's ability to meet the segment's needs considering the competitive environment. Meanwhile, the market attractiveness by M. E. Porter [3] is considered to be closely related to the competitive situation in the market, i.e. economy competitiveness of companies and the country. M. E. Porter, based on the five-forces model, argues that an attractive market is the one in which you can get the maximum profit or benefit, in other words, the more relevant market participants getting on for ideal competition, the less attractive it becomes.

Unfortunately, the exiting literature on criteria of MCTOs attractiveness is quite not so large because there are different categorization of terminal operating companies. For example, Bichoou and Bell [4] propose to divide global ports operators on four types: (1) terminal operating shipping lines which are not active in containerized cargo operations; (2) terminal operating shipping lines with terminals operated on a dedicated or a common-user basis; (3) terminal operating port authorities; (4) terminal operating companies. In turn, 
Parola and Musso [5] make a distinction among tree groups: pure stevedoring who manage terminals as profit centers; integrated carriers who manage terminals mainly as costs centers, and a group of hybrid terminal operators consisting of shipping lines involved in the stevedoring business and handling both own cargo and third-party traffic to make a profit. Slack and Frémont [6] distinguish two groups of port operators as: transnational terminal operating companies and international shipping lines. Along the same lines, Olivier [7] indicated two groups such as: transnational corporations in the terminal industry and international terminal operators who mainly are ocean carriers, they concentrate on linking terminal operations with ocean carriers business.

When we analyzed the literature we can see that may authors investigated attractiveness of terminal industry from the point of its choice by ocean carriers. Moreover, many authors identify seaport with terminal. Ha [8] has compared and evaluated the service quality factors of major container ports from the viewpoint of ocean carrier and logistics managers. The factors of importance, he has separated into seven group: (1) information viability, (2) port location, (3) port turnaround time, (4) facilities available, (5) port management, (6) port costs, and (7) customer convenience. Similar key determinants of port choice were proposed by Tongzon and Heng [9]. The authors selected the following factors: port (terminal) operation efficiency level, port cargo handling charges, reliability, port selection preferences of carriers and shippers, the depth of navigation channel, adaptability to the changing market environment, landside accessibility and port differentiation. Further studies devoted the port choice by ocean carriers have been run by: Mangan [10], Lirn et al [11], Nirn et al [12], Ahn et al [13], Tongzon and Sawan [14], Tongzon [15], Kim JinYoung [16], T. Notteboom, J-P. Rodrigue [17].

In summary, factors (determinants) of attractiveness of port choice by ocean carriers are well documented. However, there is a lack of research, which concentrate on marine container terminal sector' attractiveness from the viewpoint of MCTOs. Currently, literature on maritime container terminal market has neither tested such case, nor encountered the challenges of the implementing such attractiveness evaluation.

\section{Methodology of the Research}

The attractiveness of marine container terminal operators has been assessed by using the weighted score approach to assessment of sectors value created by G. Giereszewska and M. Romanowska [18]. The approach to that analysis has been proved and improved during the meetings with mangers of many firms. During the construction of the analysis's scheme, assuming that, the respondents of the research well-known M.E. Porter's concept "five competitive forces". In the proposed version of the approach, it is necessary to analyses 15 criteria which describe their current attractiveness for the sector's participants and enrol results of the assessment to form which includes the criterion's list with attributed weights. The maximum score which the assessment of the research may receive equally 150 points. The managers has assessed current attractiveness of the sector from its own business unit. All results received from the research has been weighted arithmetic mean.

The list of propose criterions of the MCTOs sector attractiveness has been built on Porter's model and taken into the account the most important factors of the business microenvironment. The general weighs of the criterions, the above-mentioned authors determined weights and criteria on discussion base with different companies' top managers who's filled in a strategic management form.

It should be remember that this method apparently is very easy to run, require a deep knowledge on competition environment and set a lot of traps. One of the most important trap is a subjectivism in assessment, especially in the fields of research, where the research 
are based on qualitative analysis. This problem has been indicated by the A.A. Thompson and A.J. Strickland [19], they put an attention, that results of the research depend on who are the respondents. For example, the authors indicates that the assessment of the sector will be different by current competitors, potential investors and independent specialists. The current competitors' asses a very high entry barriers very positively but potential entrants the same barriers assess very negatively because they need to invest a huge sum of money and undertake a very high risk. From the other side, the high exit barriers are very crucial for the current competitors which run business in the sector, in turn the potential investors doesn't take into account in the analysis these barriers. Therefore, it should be taken into consideration that we should distinguish real value of the assessment sector from subjective value of the assessment sector indicated by the respondents. The influence of the subjective value assessment on the result of the research is evident when the respondents' asset sector in which run their company.

The second trap which may appear in the research is the time-horizon of the assessment of the sector. So that, we might to assess the current and future perspective of the sector. Because, the research has to assess the current situation in the sector, therefore the respondents had to assess the current attractiveness which exist at the marine container terminal market.

If the know the traps and limitations of the method then we can use it very successfully for assessment of sector attractiveness. Moreover, by using the same criterions and using the same weight allows us to compare researched sector with other related and unrelated sectors.

Target respondents were practitioners in senior positions in marine container terminal operators (see table 1) with sufficient knowledge of their organization's overall activities and operations. Each item offered a five-point scale, anchored by $5=$ 'strongly important' and $1=$ 'strongly unimportant'.

Table 1. Research respondents.

\begin{tabular}{|l|c|c|}
\hline \multicolumn{1}{|c|}{ Marine container terminals } & $\begin{array}{c}\text { Terminal's } \\
\text { abbreviations }\end{array}$ & Owner \\
\hline $\begin{array}{l}\text { Baltic Container Terminal } \\
\text { Gdynia Ltd. }\end{array}$ & BCT & ICTSI \\
\hline DB Port Szczecin Ltd. & DCT & $\begin{array}{c}\text { Macquarie Infrastructure and Real } \\
\text { Assets (MIRA) }\end{array}$ \\
\hline $\begin{array}{l}\text { Deepwater Container Terminal } \\
\text { Gdańsk Ltd. }\end{array}$ & GCT & $\begin{array}{c}\text { CK Hutchison Holdings Limited } \\
\text { (CK Hutchison) }\end{array}$ \\
\hline $\begin{array}{l}\text { Gdynia Container Terminal } \\
\text { Ltd. }\end{array}$ & & OT Logistics Group S.A. \\
\hline Terminal OT Port Gdynia Ltd. & & OT Logistics Group S.A. \\
\hline $\begin{array}{l}\text { Terminal OT Port Świnoujście } \\
\text { S.A. }\end{array}$ & & \\
\hline
\end{tabular}

Own elaboration.

All responders have given its own ratings on current attractiveness of the marine container terminal industry. The weighted score has been calculated by sum up all indicated ratings and the result for every factor has been divided by amount of the investigated terminal operators. In the research all respondents belonged to top managers of the marine container terminal operators. This study sought answer for the following research questions: 
Q1. Is marine container terminal market attractive for MCTOs which are located at the Polish market?

Q2. What are the most important attractiveness criteria for MCTOs?

\section{The Factors Attractiveness Analysis and Results}

A marine container terminal is a place where container units are transferred by two or more freight transport modes. In this nodal place container units are loaded and unloaded, exchanged, stored and/or distributed. It is noteworthy that, currently in Poland, much effort is aimed at increasing the marine containers flows and the use of new generation terminals which will mean an increase in the use of the container handling operations at marine container terminals. An increase in handling can only be justified by a considerable increase in the new terminal capacity of the current terminals, a decrease in costs, or a combination of the two foregoing developments.

The marine container terminal market is defined as all marine container terminals throughout the Poland where activities are deployed in such a way that facilitate a smooth direct (or indirect) transshipment of marine containers from vessel to container yard stocks and intermodal or truck transport. There is a shape competition among sector players because actors see chances or feel pressure to improve their current positions. The attractiveness of the investigated marine container terminal operators sector depends on the following criteria:

(1) Market size/cargo volume.

(2) Market growth rates.

(3) ROI in the sector.

(4) Degree of company's concentration in the sector.

(5) Shape competitive struggle.

(6) Entry barriers.

(7) Exist barriers.

(8) Substitution threats.

(9) New competitors entrance threats.

(10) Supply assurance.

(11) Technology stability.

(12) Possibilities of service differenation.

(13) Possibility of activity diversification.

(14) Seasonality and cyclicity.

(15) Natural environment pollution threats.

The table 2 shows the results of empirical investigation of evaluation attractiveness of marine container terminal market from the viewpoint of MCTOs.

Table 2. The results of attractiveness assessment of Polish marine container terminal industry in 2018 using the weighed score approach.

Ratings are on a scale of 1 (very unattractive) to 5 (highly attractive)

\begin{tabular}{|c|l|c|c|c|}
\hline & Attractiveness criteria & $\begin{array}{c}\text { Weight } \\
\text { The range } \\
\text { from 1 to 3 } \\
\text { points }\end{array}$ & $\begin{array}{c}\text { Rating } \\
\text { Attractiveness of current } \\
\text { situation in the industry } \\
\text { (the range from 1 to 5 points) }\end{array}$ & $\begin{array}{c}\text { Weighted } \\
\text { Score }\end{array}$ \\
\cline { 5 - 5 } 1. & 3 & 4,8 & 14,4 \\
\hline 2. & Market size & 3 & 4,6 & 13,8 \\
\hline 3. & Rarket growth rate & 3 & 3,6 & 10,8 \\
\hline
\end{tabular}




\begin{tabular}{|r|l|c|c|c|}
\hline 4. & $\begin{array}{l}\text { Concentration degree } \\
\text { in the sector }\end{array}$ & 1 & 3,6 & 3,6 \\
\hline 5. & $\begin{array}{l}\text { Shape competitive } \\
\text { struggle }\end{array}$ & 3 & 4,4 & 13,2 \\
\hline 6. & Barriers entrance & 3 & 4 & 12 \\
\hline 7. & Exist entrance & 1 & 3,4 & 3,4 \\
\hline 8. & Substitution threats & 2 & 2,6 & 5,2 \\
\hline 9. & $\begin{array}{l}\text { New competitors } \\
\text { entrance threats }\end{array}$ & 3 & 3 & 9 \\
\hline 10. & Supply assurance & 1 & 3,6 & 3,6 \\
\hline 11. & Technology stability & 2 & 3,6 & 7,2 \\
\hline 12. & $\begin{array}{l}\text { Possibilities of service } \\
\text { differentiation }\end{array}$ & 2 & 4 & 7,6 \\
\hline 13. & $\begin{array}{l}\text { Possibilities of } \\
\text { activity diversification }\end{array}$ & 1 & 2,6 & 4 \\
\hline 14. & $\begin{array}{l}\text { Seasonality and } \\
\text { cyclisity }\end{array}$ & 1 & 1 & 111,4 \\
\hline 15 & $\begin{array}{l}\text { Threats of natural } \\
\text { environment pollution }\end{array}$ & 1 & 52,6 & \\
\hline 16. & $\begin{array}{l}\text { Sum the weighted } \\
\text { rating scale }\end{array}$ & 30 & & \\
\hline
\end{tabular}

Own elaborated.

The market size/cargo volume factor is present in 1 out of 15 evaluation criteria shown in Table 2. The respondents have indicated that this factor is the most relevant for the decision makers in this investigated sector. The attractiveness of current situation in this sector has been estimated very high $(4,8)$, and the sum of the weighted rating score $(14,4)$. The larger the market, the more attractive it is, because it gives opportunities to quick development of the MCTOs (see figure 1). Additionally, a larger market can indicate the market attractiveness to other companies. Currently, we have a very huge increase of marine container market size measured by loaded and unloaded TEU units in Poland.

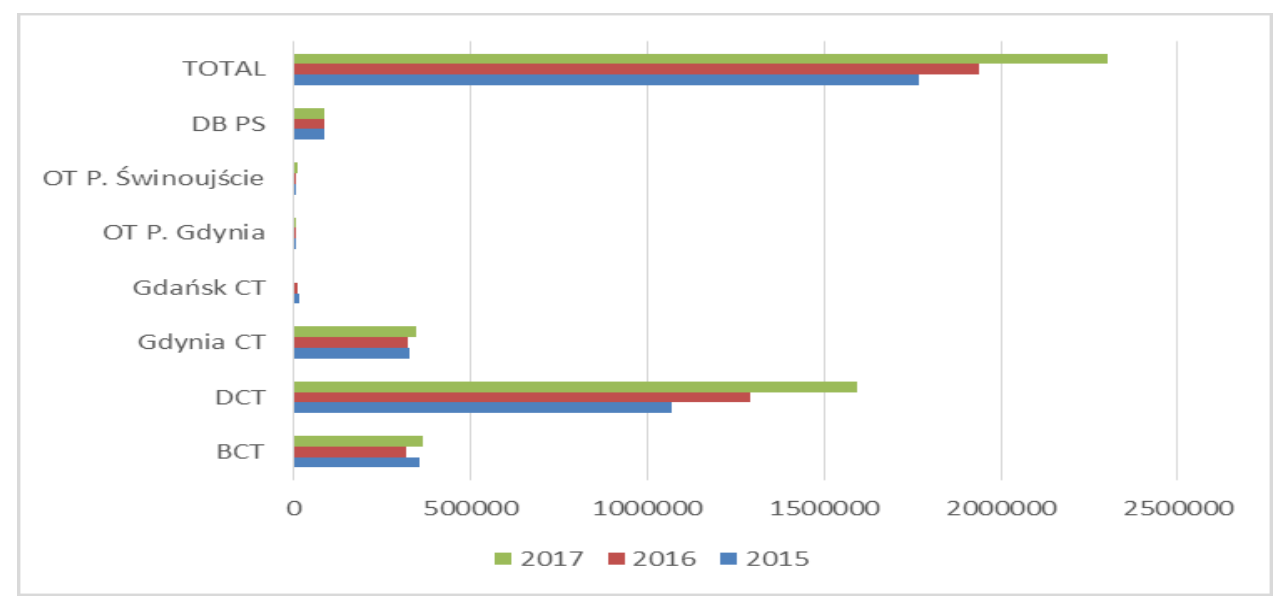


Figure 1. Marine container turnover in Poland 2015-2017 [in TEU]. Own elaborated.

Market growth rate factor indicates the rate at which a marine container terminal market's size is increasing. The market growth rate, as a second of the fundamental factors of marine container terminal market competitiveness, has been present in 2 out of 15 results shown in Table 2. The respondents have indicated that this factor also is the most relevant for the decision makers in marine container terminal sector. The importance of present situation in the sector has been estimated very high by respondents, reaching this results at $(4,6)$, and the sum of the weighted rating score $(13,8)$. This factor is expressed as an annual percentage of container units loaded or unloaded by all MCTOs per annum. Historically high growth rates do not always indicate a high rate of growth looking into the future as sectoral and economic conditions change constantly and are often cyclical (see table 3). Anyway, the market growth rate is gained result $18,74 \%$ in 2017 year in Poland. So if, MCTO's customers have high demand, container market growth is quick. If marine container terminal operator develop terminal services assortment or built its service loyalty at a specific price level, than marine container market growth also should increase. The larger the market growth rate factor, the more attractive it is, because it gives opportunities to quick development of current MCTOs.

Table 3. Market container growth rates in Poland during 1994-2017 periods

\begin{tabular}{|c|c|c|c|c|c|}
\hline $\mathbf{1 9 9 4}$ & $\mathbf{1 9 9 5}$ & $\mathbf{1 9 9 6}$ & $\mathbf{1 9 9 7}$ & $\mathbf{1 9 9 8}$ & $\mathbf{1 9 9 9}$ \\
\hline $6,67 \%$ & $14,98 \%$ & $11,12 \%$ & $13,61 \%$ & $20,35 \%$ & $-9,03 \%$ \\
\hline $\mathbf{2 0 0 0}$ & $\mathbf{2 0 0 1}$ & $\mathbf{2 0 0 2}$ & $\mathbf{2 0 0 3}$ & $\mathbf{2 0 0 4}$ & $\mathbf{2 0 0 5}$ \\
\hline $16,01 \%$ & $15,43 \%$ & $11,72 \%$ & $20,53 \%$ & $27,86 \%$ & $12,08 \%$ \\
\hline $\mathbf{2 0 0 6}$ & $\mathbf{2 0 0 7}$ & $\mathbf{2 0 0 8}$ & $\mathbf{2 0 0 9}$ & $\mathbf{2 0 1 0}$ & $\mathbf{2 0 1 1}$ \\
\hline $13,97 \%$ & $32,09 \%$ & $1,29 \%$ & $-12,94 \%$ & $57,80 \%$ & $27,65 \%$ \\
\hline $\mathbf{2 0 1 2}$ & $\mathbf{2 0 1 3}$ & $\mathbf{2 0 1 4}$ & $\mathbf{2 0 1 5}$ & $\mathbf{2 0 1 6}$ & $\mathbf{2 0 1 7}$ \\
\hline $23,21 \%$ & $15,31 \%$ & $7,96 \%$ & $-14,02 \%$ & $9,62 \%$ & $18,74 \%$ \\
\hline
\end{tabular}

Own elaborated.

The next factor which is very important for evaluating attractiveness of the investigated sector is its return of investment. This factor is a performance measure used to evaluate the efficiency of an investment in marine container terminal or compare the efficiency of a number of different others investments. Anyway, the higher ROI, the higher attractiveness of the analyzed sector. This factor has been present in 3 out of 15 evaluations criteria shown in Table 2. The respondents have indicated that this factor is relevant for the top decision makers employed in all MCTOs. The importance of this factor for current situation in this sector has been estimated high $(3,6)$, and the sum of the weighted rating score $(10,8)$.

The concentration degree of marine container terminal operators in the sector is not relevant for MCTOs decision makers. This factor has been present in 4 out of 15 evaluations criteria shown in Table 2. The respondents have indicated that this factor is not 
so much important for them. The importance of this criteria for present situation in this sector has been estimated at level $(3,6)$, and the sum of the weighted rating score resulting $(3,6)$.

We need to pay attention that, investigated sector in Poland, has an oligopolistic competition because there are only six main players such as: Baltic Container Terminal Ltd, (located in Gdynia seaport), Gdynia Container Terminal Inc. (located in Gdynia seaport), OT Logistic Terminal Gdynia (located in Gdynia seaport), Deepwater Container Terminal Inc. (located in Gdansk seaport), Gdansk Container Terminal Inc. (located in Gdansk), OT Logistic Terminal (Located in Szczecin-Świnoujście seaport), and finally DB Schenker Terminal Inc. (located in Szczecin-Świnoujście seaport). Unfortunately, Gdansk Container Terminal Inc. is under liquidation proceedings. The above-mentioned marine container terminal operators compete with each other to provide the best services at their terminals for the lowest possible price. The Deepwater Container Terminal Operator gains some advantages because of the terminal's localization (natural deep-water channel at seaport), and receives also additional benefits such as: direct calls ocean carriers at the terminal (for example: 2M Alliance «Hyundai Merchant Marine also uses this loop service», Ocean Alliance), a higher terminal services rates for box then offered by other container terminal operators (higher THC - Terminal Handling Costs), and a faster and higher increase of containers throughputs. So, DCT Gdansk is operating as a hub [20] for others containers terminals located at Baltic Sea. The high degree of competition concentration it means that one marine container terminal operator may become a regional sector maker and impose others MCTOs its own market game rules. Currently, such status of reginal sector maker has DCT Gdansk in Poland. Moreover, the high degree of competition concentration in this sector comes from oligopoly power, because of technologies and economics rules, where terminal services production and its sales must be done at large economic scale to be economic profitable.

The shape competitive struggle factor is another relevant factor of sector attractiveness. This factor has been present in 5 out of 15 evaluations criteria shown in Table 2. The respondents have indicated that this factor is relevant for the decision makers in this investigated sector. The importance of this criteria for a present situation in this sector has been estimated very high $(4,4)$, and the sum of the weighted rating score $(10,8)$.

The highest the sector's attractiveness, the lowers a competitive struggle among competitors. The most important information for the potential new comers to the sector is a knowledge on a form a competition. The potential new comers don't want to enter into the sector if there is a shape price war among the competitors. According to all respondents of the investigation there is a strong shape price war in the marine container terminal market in Poland. In the market, we have two important groups of industry competitors. So we can distinguish here, the passive and active marine container terminal operators. The passive operators are Port Authorities and active operators are real terminal services providers. The first group (passive operators-Ports Authorities) consists of container terminal infrastructure owners who are not providing the terminal services by themselves. The only services they provide are some facilitations for the marine container terminal services operators. This group of passive operators are responsible for construction, modernization, development and maintains terminal infrastructure such as: yard stocks, berths, quay, offices space, storages, sheds, warehouses, rail (multimodal) and road infrastructure. These terminal infrastructure requires huge capital investments. Basically, there is, in Poland, only one form of terminal infrastructure ownership: state and municipal-owned terminals. Anyway, whole marine container terminal infrastructure belongs to public and municipal authorities as well. The public container terminal owner (seaports authorities) has to develop terminal infrastructure investments which allow to attract the real marine container terminal operators into the seaport. In this way, the real (active) marine container terminal operator 
does not lose the time and money for constructing new infrastructure terminal investments and he can mainly concentrate on its own core activity. The main goal of the Polish seaports authorities is to facilitate the central terminal services, or to put it simply by granting concession on container terminal infrastructure per square meters. The price for the square meters depends on the negotiation skills of both parties, on the total square meter volume and the terminal location, and on the market power of both parties. The price is also influenced by the quality of the delivered infrastructure square meters (for example, a new or old rail container terminal infrastructure) [21].

The second group of "sector competitors" consists of the real (active) marine container terminal operators whose provide the terminal service assortment. The marine container terminal operation can be accomplished by international terminal operators (Baltic Container Terminal Ltd. - belonging to ICTSI - International Container Terminal Services Inc. Manila; Gdynia Container Terminal Inc. - belonging to HPH - Hutchinson Port Holding - Hong Kong), rail and logistics operators (DB Schenker Terminal ltd.), capital investors (OT Logistics Terminal Gdynia and Szczecin- Świonujscie - private equity; The Deepwater Container Terminal Gdansk - pension funds). Till now, there is no marine container terminal which is operating by ocean carrier, feeder service carrier, logistics operators or public authorities. However, this situation may change if the capital investors (pension funds or private equity) would like to sell its stocks to above-mentioned potential customer's group. The marine container terminal operator is particularly interested in the costs' optimizing of the terminal services provided to its customers. The costs' optimizing means such looking for costs' saving which are not negatively impact on quality services provided by real MTCO.

Entry barriers factor is that protect "sector competitors" from new entrants to the sector. This factor is present in 6 out of 15 evaluations criteria shown in Table 2. The respondents have indicated that this factor is relevant for the decision makers in this investigated sector. The importance this criteria for a current situation in this sector has been estimated very high $(4,0)$, and the sum of the weighted rating score (12).

Exit barriers factor is that keep a "sector competitor" in the market, even if the return on investment is too low or even negative. This factor is present in 7 out of 15 evaluations criteria shown in Table 2. The respondents have indicated that this factor is relevant for the decision makers in this investigated sector. The importance of this criteria for a present situation in this sector has been estimated very high $(3,6)$, and the sum of the weighted rating score $(10,8)$.

This is especially true of the container terminal market: high investments in different types of vehicles and other terminal facilities (medium or long-term leasing contracts) impose a major exit barrier for the container terminal operator who is already active in the market. The exist barriers may be different for marine container terminal operators which are operate on international and local market. The real international marine container terminal operators may decide to move its own terminal superstructure (yard trucks, AGVs, yard cranes, quay cranes and so on) into the other marine container terminals, which belong to its portfolio if the ROI will be too low or even negative. Contrary to real international container terminal operators will be local terminal operators, which has not possibilities to shift terminal superstructure to another terminal. In that case, exist barrier for local container terminal operator will be higher than for international marine container terminal operator. Exit barriers are relatively low and the entry barriers relatively high this automatically means that the profits in the marine container terminal market can only be high and not very risky. It should be indicated that exist barriers in the investigated sector are very important because they are high; once a marine container terminal is in use, it is relatively difficult to quit the operations because of the huge initial investments which are needed to start operations. 
The substitution threats factor may decrease the potential profits of a sector by imposing a barrier on the prices sector competitors. This factor is present in 8 out of 15 evaluations criteria shown in Table 2. The respondents have indicated that this factor is not relevant for the decision makers in this investigated sector. The importance of this criteria for a present situation in this sector has been estimated very low $(2,6)$, and the sum of the weighted rating score $(5,2)$. Each market will have to deal with options that replace current services or products that industry competitors produce. Substitutes for the use of a marine container terminal are surprisingly one of the strongest competitive forces in the market. The most important substitutes in the marine container terminal market are unimodal road and intermodal rail transport. The position of the both transport modes are extremely strong, especially when they carry containers passing over the marine container terminals. This can either be caused by the very competitive solutions offered by unimodal road and intermodal rail transport, by the weak developed link between marine container terminal operator and its hinterland.

New entrants threats factor into the marine container terminal market is newly constructed terminals. This factor is present in 9 out of 15 evaluations criteria shown in Table 2. The respondents have indicated that this factor is a medium relevant for the decision makers in this investigated sector. The importance of this criteria for a current situation in this sector has been estimated medium $(3,0)$, and the sum of the weighted rating score $(9,0)$. The new active marine container terminals will increase capacity as well as competition in the terminal market in a specific terminal service area and thus impact utilization rates of existing terminals. This could result in lower prices and/or higher terminal operation costs and also the transport network could be affected. Even if no extra terminal capacity is added, the take-over of a terminal operator to create a market position also means the entrance of a new industry competitor. This situation takes place when owner of the terminal's infrastructure (passive terminal owner) would like to enter into the terminal operational functions. This game player may not extend a concession agreement with real (active terminal operator) marine container terminal operator and thus take-over resources (mainly human resources whose have the best know-how on terminal operations) created by the previous MCTO. The risk of this situation depends upon ruling political party. The higher risk when ruling Conservative Party, and the lower risk when ruling Liberal Party. Moreover, the potential entrants into the marine container market have quite large barrier because the best places for terminal localization in the seaport area are occupied by the current operating MCTOs in the sector.

Terminal facilities supply assurance factor covers suppliers of technical equipment, mass media, infrastructure and capital resources (money). This factor is present in 10 out of 15 evaluations criteria shown in Table 2 . The respondents have indicated that this factor is not relevant for the decision makers in this investigated sector. The importance of this attractiveness criteria for a present situation in this sector has been estimated very low $(3,6)$, and the sum of the weighted rating score $(3,6)$. These suppliers can use their economic power, for example, by raising prices and lowering the quality of their goods and/or services. Another option for the supplier is to threaten integrating of terminal services into their own assortment. The strength of this force further depends on the number of suppliers; if the suppliers of terminal infrastructure are concentrated, in general they have greater economic and bargain power.

Here we will pay attention to technology stability factor. This factor is present in 11 out of 15 evaluations criteria shown in Table 2. The respondents have indicated that this factor is relevant for the decision makers in this investigated sector. The importance of this attractiveness criteria for a current situation in this sector has been estimated medium level $(3,6)$, and the sum of the weighted rating score $(7,2)$. High degree of used containers technology also influence on high quality services provided by MCTOs. Every MCTO 
definite some requirements concerning on container technology use in terminal to aim archiving better competitive advantage over others competitors. The technology influence on amount of capital expenditure used to purchase the technology, technical equipment and on operation organization. The used technology in marine container terminals is quite stable. According to all respondents, marine container terminal technology changes longer than 5 years. Many container terminal operators significant gain in productivity were achieved through advanced terminal layouts, more efficient IT- support ("micro-pcs") and improved logistic control software systems, as well as automated transportation and handling equipment.

Possibilities of service differenation factor. This factor is present in 12 out of 15 evaluations criteria shown in Table 2. The respondents have indicated that this factor is relevant for the decision makers in this investigated sector. The importance of this factor for a present situation in this sector has been estimated low level $(3,8)$, and the sum of the weighted rating score $(7,6)$. The main goal of MCTOs is to provide terminal services that are requested by customers such as: shipping owners, forwarders, logistics operators and so on. In order to provide the best terminal services, the MCTOs should create product which is the terminal service assortment. This assortment differ from terminal to terminal and can be both thick and broad. Moreover, the MCTO may broad its terminal service assortment on: storage, assembling, repacking, consolidating, configuring, cautrylizing, quality controlling, and customizing, packing, finishing, merging, testing, barcode labeling, tracking and tracking and so on. The MCTOs will assure that the terminal service assortment fits into the logistical chain of customers. In this sector, it is very hard to create strong position of the product mark or the company brand. Unfortunately, all respondents of the marine container terminal operators indicated that the customers (especially forwarders) are not loyal to the terminal services providers. The customers (forwarders) change the MCTO very often. The lack of creation of any terminal services mark or company brand in the analyzed market runs to strong increase of shape competitive struggle because there are any possibilities to create some psychologic costs for customers, which theirs should bear, if customer tries to change one service terminal provider to another. The customers transition 'form one marine container terminal operator to another is easy because the container terminals are located very close to each other.

Possibility of activity diversification factor. This factor is present in 13 out of 15 evaluations criteria shown in Table 2. The respondents have indicated that this factor is not relevant for the decision makers in this investigated sector. The importance of the attractiveness criteria for a present situation in this sector has been estimated low $(4,0)$, and the sum of the weighted rating score $(4,0)$. Some MTCOs diversify them activity by entering into the additional terminal services as heavy lift cargo transshipment.

Seasonality and cyclicity factor. This factor is present in 14 out of 15 evaluations criteria shown in Table 2. The respondents have indicated that this factor is completely no relevant for the decision makers in this investigated sector. The importance of the attractiveness criteria for a current situation in this sector has been estimated very low $(2,6)$, and the sum of the weighted rating score $(2,6)$.

In the container activity, we have problem with periodicity which run to terminal production capacity surplus. This situation appeared in the global market during the world crisis in 2007, when containers throughputs has gone down very rapidly. This crisis has driven MCTOs to strong intense competition, because the terminal services providers fight to fill its free terminal production capacity.

The seasonality in marine container terminals has two reasons and is directly connected with the seaborne commodity trades. An important cause of short-term volatility is the seasonality of some commodities carried in marine containers. Nowadays, many agricultural commodities are transported in marine containers and they are subject to 
seasonal fluctuations caused by harvests, such as: grain, sugar, citrus fruits and others [22]. Moreover seasonality in containerization exist with major holidays such as the Chinese New Year and Christmas, Easter and other local feast days, for example in Poland, All Souls' Day.

The last Natural environment pollution threats factor. This factor is present in 15 out of 15 evaluations criteria shown in Table 2. The respondents have indicated that this factor is completely not relevant for the decision makers in this investigated sector. The importance of the attractiveness criteria for a present situation in this sector has been estimated very low $(1,0)$, and the sum of the weighted rating score $(1,0)$. According to the respondents this factor is not relevant for attractive analyzed sector. The answer is quite interesting because there is international policy which concentrate on using low-emission or non-emission cargo handling equipment vehicles.

The evaluation of the attractiveness of the sector is carried out on the base of comparison with other sectors. Unfortunately, we do not have such data and information on attractiveness of other sectors. Therefore, at the end of this analysis we had to create some determine category of the sector. In this aim, we have to sum the weighted rating score and determine category of sector as follows:

1. High attractiveness of the sector $\quad=>(150 ; 135)$.

2. Satisfactory attractiveness of the sector $=>(134 ; 91)$.

3. Weak attractiveness of the sector $\quad=>(90 ; 70)$.

4. Critical attractiveness of the sector $=>(69 ; 50)$.

According to the approach above-described we can say that analyzed sector of marine container terminal located in Poland is satisfactory for MTCOs cause total achieved sum equals 111.4. This research, above all, contributes to understanding that attractiveness evaluation of marine container terminal sector depends heavily on such factors as: market size/cargo volume, shape competitive struggle, market growth rate, barriers entrance and return of investment.

\section{Conclusions and Proposals}

This paper applies evaluation attractiveness approach to assess a marine container terminal attractiveness in Poland through analyzing a survey of six marine container terminals operators. It provides empirical analysis to support the unique and interesting findings that the most important factors influencing marine container terminal operators' investing decisions are: market size/cargo volume, market growth rate, shape competitive struggle, entry barriers and return of investment. It triggers further discussion on marine container terminal operator's competitive factors and development strategies. For instance, it is arguable to ascertain the attractiveness of investigated sector is satisfactory attractive for MCTOs operating in Poland. Market size/ cargo volume, market growth rate become important criteria only when a seaport's infrastructure, draught and its national's political stability satisfy MCTO's basic requirements. The lesson learned from the investigation indicated that market size/ cargo volume, market growth rate, sharp competitive struggle, entry barriers and return of investment, having over 64,2 points importance among the 15 criteria, largely determine the MCTOs attractiveness in Poland.

\section{References}

[1] T. Bebbington, 50,000 TEU... the Future or Not?, Maritime Executive, https://maritime-executive.com/ediorials/50000-teu-the-future-or-not. (12.02.2018) 
[2] O. Pryhara, Techniques for Analyzing the Attractiveness of International Commodity Markets under Conditions of Economic Globalization, Vol. 14, p. 27 (2006)

[3] M. E. Porter, Competitive Strategy: Techniques for Analyzing Industries and Competitors. New York, N.Y.: Free Press, p. 396 (1980)

[4] K. Bichou, M. Bell, Internationalisation and consolidation of container port industry: Assessment of channel structure and relationships, Maritime Economics and Logistics, 9: 33-51, (2007)

[5] F. Parola, E. Musso, Market structures and competitive strategies: The carrierstevedore arm-wrestling in northern European ports, Maritime Policy and Management, 34 (3): 259-278 (2007)

[6] B. Slack, A. Frémont, Transformation of port terminal operations: From the local to the global, Transport Review, 25(1): 117-130, (2005)

[7] D. Olivier, Private entry and emerging partnerships in the container terminal industry: Evidance from Asia, Maritime Economics and Logistics, 7(2): 87-115 (2005)

[8] M. Ha, A comparison of service quality at major container ports: Implication for Korean ports, Journal of Transport Geography 11(2):131-137 (2003)

[9] J. Tongzon, W. Heng, Port privatisation, efficiency and competitiveness: some empirical evidence from container ports. Transportation Research Part A 39(5): 405 424 (2005)

[10] J. Mangan, C. Lalwani, B. Gardner, Modelling port/ferry choice in RORO freight transportation, International Journal of Transport Management 1(1): 15-28 (2002)

[11] T. Lirn, H.A. Thnopoulou, A.K. Beresford, Transhipment port selection and decisionmaking behaviour: Analysing the Taiwanese case. International Journal of Logistics: Research and Applications 6(4): 229-244 (2003)

[12] A. Nir, K. Lin, G. Liang, Port choice behaviour - From the perspective of the shipper, Maritime Policy \& Management 30(2): 165-173 (2003)

[12] W. Ahn, S. Lim, S. Ahn, A study on analyzing bottlenecks of logistics in Incheon Port. Focused on container freight. Korean Research of Logistics 14(2): 65-90, (2006)

[14] J. Tongzon, L. Sawant, Port choice in a competitive environment: From the shipping liea's perspective. Applied Economics 39(4): 4777-492 (2007)

[15] J. Tongzon, Port choice and freight forwarders. Transportation Research Port E 45(1): 186-195 (2009)

[16] Kim J-Y., Port user typology and representations of port choice behaviour: A Qmethodological study. Martime Economics \& Logistics 16(2): 165-187 (2014)

[17] T. Notteboom, J-P. Rodrigues, The corporate geography of global container terminal operators, Martime Policy \& Management, 39(3): 249-279, (2012)

[18] G. Giereszewska and M. Romanowska, Analiza strategiczna przedsiębiorstwa, PWE, $122-126(2003)$

[19] I. Urbanyi, M. Klopott, Container terminals and port city interface - a study of Gdynia and Gdańsk ports, Transportation Research Procedia 16 ( 2016 ): 517 - 526 (2016)

[20] A.A. Thompson, A.J. Strickland, Strategic Management. Concepts and Cases, R.D. Irwin, Homewood, Ill, Boston, p. 225, (1996)

[21] B. W. Wiegmans, E. Masurel,P. Nijkamp, Intermodal freight terminals: an analysis of the terminal market, Transportation Planning and Technology, 23: 105-128 (1999)

[22] M. Stopford, Maritime Economics, Routledge, London and N.Y., p. 97 (2009) 